\title{
LA-ICP-MS on hardened cement paste: laser-material interaction, signal formation and optimization of laser fluence
}

\author{
M. Decker $\cdot$ J. Siegel $\cdot$ H. Hilbig $\cdot$ D. Heinz
}

Received: 4 March 2021/Accepted: 11 June 2021/Published online: 30 June 2021

(C) The Author(s) 2021

\begin{abstract}
In almost all applications of concrete components, both the transport of substances such as chlorides, sulphates, acids, $\mathrm{CO}_{2}$, etc. through the pore structure into the concrete and the resulting local chemical and physical processes have a negative effect on the lifetime of the structure. Most data are actually obtained from layer-by-layer mechanical sampling of, for instance, bore dust, followed by chemical analysis. Several groups have previously demonstrated the enormous potential of LA-ICP-MS for monitoring these multi element processes both qualitatively and quantitatively and with high spatial resolution. However, there has been no fundamental investigation of laser-material interaction, aerosol particle formation, fractionation analysis or the effect of cement-specific parameters such as the water to cement $(w / c)$ ratio on signal intensity. This paper presents the ablation mechanisms of a frequently used $213 \mathrm{~nm}$ quintupled Nd:YAG ns laser operating on the HCP (hardened cement paste) multi-phase system in comparison with amorphous and well-characterized NIST 612 glass. It includes energy-signal considerations, crater
\end{abstract}

Supplementary Information The online version contains supplementary material available at https://doi.org/10.1617/ s11527-021-01736-4.

M. Decker · J. Siegel $\cdot$ H. Hilbig $(\bowtie) \cdot$ D. Heinz Center for Building Materials, Technical University of Munich, Franz-Langinger-Straße 10, 81245 Munich, Germany

e-mail: harald.hilbig@tum.de evaluations after multiple shots using different energy densities and aerosol structures captured on filters. The investigation determined a linear energy to signal behavior in a range of $2-6 \mathrm{~J} / \mathrm{cm}^{2}$, while the ablation mechanism is different to common mechanisms obtained for glass or brass. The aerosol captured on the filter material displays cotton-like structures as well as defined spherical particles, which is comparable to observations made with NIST glass aerosols.

Keywords Laser ablation - ICP MS · Hardened cement paste $\cdot$ Fractionation $\cdot$ Ablation mechanism

\section{Introduction}

As concrete is a widely used material for the construction of bridges, roads, houses, water pipes and sewers, etc. an essential factor is that they have a long lifetime. Concrete is generally made up of aggregates and sand, with hardened cement paste (HCP) as a binding agent. The hydration reaction is initiated by adding water to the cement. A kinetically driven dissolution and precipitation of various nanocrystalline phases then begins to form the firmness-forming HCP. The nanocrystalline needles are an alternating network of numerous mineralogical phases, such as portlandite, ettringite and amorphous $\mathrm{C}-\mathrm{S}-\mathrm{H}$ phases, all of them containing significant amounts of chemically bound water [1]. However, as 
the reaction with water is kinetically hindered, thus, unreacted cement is still found after the standard age of 28 days. Moreover, besides the nanocrystalline needles, and depending on the water to cement ratio and the age of the sample, HCP contains a significant amount of pores of various sizes, which are mostly filled with water [2]. The porosity decreases with decreasing $w / c$ ratio and increasing age as, over time, the crystal needles overgrow the pores [2,3]. It is the numerous transport reactions like chloride or sulphur ingress that are responsible for the destruction of concrete, while in most cases HCP is the material that is affected by incoming substances [4]. Thus, HCP can be regarded as that element of a concrete structure that determines its service lifetime [5].

LA-ICP-MS is in wide general use as an analytical method for isotope detection and is mainly used to determine the age of geological samples or for spatially resolved elemental mapping of heavy metals in biological tissue [6, 7]. However, LA-ICP-MS is also a suitable tool for use in the kind of deterioration processes in HCP described above, as it allows a high spatial resolution along with multi-element analysis. Huber et al. monitored the ingress of biogenic sulphuric acid into concrete [8] and HCP [9]. Bonta demonstrated an application involving chloride intake into a bridge pillar in Austria, in which the benefits of LA-ICP-MS compared to the commonly used method of borehole drilling were readily apparent [10]. Silva focused on the calibration of chloride determination in HCP and chloride ingress kinetics in HCP and concrete to investigate the effect of chlorides on rebar corrosion [11]. Other applications involving concrete, with a focus on the detection of radionuclides in concrete exposed to radioactive radiation are also presented in the literature $[12,13]$.

Nevertheless, one drawback of the method is that it lacks a system of calibration [14, 15]. For this reason, many groups $[10,12,16,17]$ employed their own, custom-made calibration standards in the various applications, in which the matrix material (here concrete or HCP) was doped with the element of interest in different amounts to produce at least a three-point calibration line. However, because the ablation behavior between concrete samples and pressed cement standards on the one hand and the ablation and ICP signal characteristics on the other can differ significantly [18], Bonta employed an internal standard. Calcium is a major constituent of HCP (if
OPC is used as cement) that is present in relatively constant concentrations (around 55-65 wt\% $\mathrm{CaO}$ for OPC [4]). In the opinion of the authors, it is therefore a suitable internal standard [10].

Although the groups yielded good results and validated their results by comparing LA-ICP-MS data with absolute methods (e.g. potentiometric titration of chlorides [10] for their special research tasks), a more detailed investigation of the ablation behavior of concrete structures is needed in order to achieve a more general insight to their specific microstructure and the varying micro and macro composition. As concrete is a multi-phase system, whose elements can be present in numerous phases e.g. $\mathrm{Ca}$ in calcite, calcium-aluminum hydrate, ettringite, portlandite, $\mathrm{C}-$ $\mathrm{S}-\mathrm{H}$ etc. [19], it is predestined for fractionation. Fractionation is a key problem that leads to an unrepresentative aerosol composition and, in turn, incorrect results. The sources of fractionation are numerous, and it can occur during ablation, transport or ionization in the ICP-plasma [20-24]. Avoiding fractionation requires a stable and well-optimized setup along with a thorough understanding of the processes going on during LA-ICP-MS. However, there has been no detailed discussion of the ablation mechanism in such nanostructured and porous materials so far in the literature, while the ablation mechanisms operating in bulk materials $\left(\mathrm{CaCO}_{3}\right.$ [25], brass, iron and steel [26-29], silicon [30], glass [31]) and most standard reference materials have been investigated in detail.

Investigations of the form and shape of ablated craters have been undertaken in the literature to find out more about ablation and its predominant mechanisms. Metals like brass and gold display large melting residues on crater edges, bottoms and -most characteristically- ejected liquid droplets outside the crater [22, 23]. Very large so-called chimneys of evaporated and recondensed material on the cooler crater edge have been observed with copper, zinc and gold [24, 28, 32]. Melting residues in and around the craters were found for glass, along with a spherical microtextured structure on the crater bottom, yielding fractionation after ablation with an ns laser [32-34]. A comparison of craters after LA using lasers of different wavelengths showed the deepest and most undefined craters for $266 \mathrm{~nm}$, while $213 \mathrm{~nm}$ and $193 \mathrm{~nm}$ showed much smoother and shallower ones [35]. Crystalline material seems to behave differently as can be seen 
with biogenic calcium carbonate, where an undefined ablation of micro crystals is observed, which seems to yield spalled craters with a $213 \mathrm{~nm}$ laser, but defined craters with a $193 \mathrm{~nm}$ laser, respectively [25]. Femtosecond laser ablation on gold, brass and glass showed more defined craters with fewer melting residues compared to ns LA [20, 28, 36, 37].

The size and shape of the particles entering the ICP are defined by the interaction of the laser with the material, showing that the ablation mechanism is a major source of fractionation. Kuhn and Günther observed that glass particles larger than $150 \mathrm{~nm}$ cannot be fully processed in ICP [38], thus leading to fractionation [39]. The particle structure is therefore very significant, while different particle formation mechanisms are presented for different materials, such as glass and brass. Bogaerts et al. [40] described the formation of particles of brass in a melting/condensation mechanism, yielding a condensated cotton-like structure. Larger particles can be produced by hydrodynamic sputtering, a mechanism described in detail by Hergenröder [23]. This model is based on the direct ejection of particles via plasma-initiated KelvinHelmholtz instabilities within the melt layer after the laser pulse, resulting in larger spherical particles. Both particle types have off-stoichiometric and thus fractionated elemental compositions [23, 27].

For insulators like glass, Kuhn et al. observed different particle shapes resulting from the two different ablation mechanisms. In their experiment, particles from 100 ablation pulses were collected on filters to determine the overall size and shape of the aerosol from two different laser wavelengths. A gridlike structure of particles smaller than approximately $10 \mathrm{~nm}$ was observed on the filter surface. Condensation from the vapor phase was the most probable origin of these particles. The aerosol, produced at a wavelength of $266 \mathrm{~nm}$, contained significant quantities of spherical particles ranging in size up to $2 \mu \mathrm{m}$. It was shown on the NIST SRM 610 standard glass series that more large, spherical particles in the $\mu \mathrm{m}$ range are generated in the order: $266 \mathrm{~nm}>213 \mathrm{~nm}>193 \mathrm{~nm}$. For fs lasers, particles are generally smaller and thus tend less towards fractionation [20].

In the case of dark BCR-2G basaltic glass, only vapor condensation and agglomeration were observed. In contrast, the agglomerates generated after LA on transparent fluorite $\left(\mathrm{CaF}_{2}\right)$, which is one of the most transparent materials in the vacuum ultraviolet spectral range (VUV, 10-200 nm), are larger and have a more cotton-like structure than glass. Most studies dealing with the analysis of particles formed by laser ablation compare different laser wavelengths or even the difference between laser types (ns vs. fs Laser $[26,27]$ and several ns lasers, such as Excimer, $\mathrm{Nd}$ :YAG, KrF [41] etc.). However, to capture the particles, filters [22, 29, 31, 33], TEM grids or membranes [27, 33, 41], or silicon substrates [28] were used to collect the particles from the gas stream. To obtain more detailed information about particle flow, several groups measured highly time resolved particle size distributions using LA-ICP-MS analysis in addition to aerosol spectrometers and electrical mobility measurements [33, 42, 43].

Size and shape tendencies among particles resulting from different materials are hard to predict. Kuhn stated from his results that differently shaped agglomerates must be expected for each sample matrix [31]. However, numerous experiments and theoretical calculations show that highly agglomerated nm-sized [44] and $\mu \mathrm{m}$-sized spherical particles can be expected for nearly every semi- or non-conductive matrix, depending on the type and pressure of carrier gas used during ablation, the chemical composition, and the absorptivity of the matrix [31]. As HCP is a mixture of multiple phases, a prediction is hard to give, thus only an empirical study can produce meaningful results.

This paper focuses on the general interaction of a $213 \mathrm{~nm}$ quintupled Nd:YAG ns laser with $\mathrm{HCP}$ compared to other materials such as glass, that are frequently investigated in the literature. As HCP has a specific microstructure of needles and crystals that have grown together and pores of various sizes, a detailed knowledge of general laser parameters, and in particular of working fluence and ablation behaviors is of great importance, so as to avoid fractionation of this multi-phase system. Not only the sizes and shapes of particles resulting from the ablation process are investigated in this paper, but also the shape and depth of the crater and the resulting ICP-MS signal.

A variety of commonly used $w / c$ ratios for HCP was examined, ranging from 0.25 , which is a mixture with low workability, to 0.50 , which tends to bleed extremely if not handled properly. The focus was on the effect of the various microscopic structures and densities of the mixtures on the ablation and ICP-MS signal. Additionally, pressed pellets of ground HCP (pHCP) with a $w / c$ ratio of 0.40 were investigated to 
obtain knowledge of ablation and aerosol structure for use in potential in-house standards.

\section{Experimental}

\subsection{Specimen preparation (HCP)}

Cement (OPC: CEM I 42.5 R, Schwenk Cement) and water were mixed according to DIN EN 196-1. After $24 \mathrm{~h}$ in a climate chamber $\left(20^{\circ} \mathrm{C}\right.$ and $98 \%$ humidity), the specimens were stored for 56 days in water. The samples were sawn with a Bühler IsoMet 5000 highprecision saw and dried for $24 \mathrm{~h}$ in a vacuum oven at $40{ }^{\circ} \mathrm{C}$ and 50 mbar prior to LA-ICP-MS analysis. In all cases, the hardened cement paste samples were packed airtight and dry after sample preparation and stored over drying agents, to ensure equal moisture content in all samples during measurement. In general, a high residual moisture in the hardened cement paste should be avoided, as it would lead to unwanted polyatomic interferences during measurement.

\subsection{Pressed pellets (pHCP, pC)}

Residual moisture from the 56 days in water storage was dabbed off the HCP prisms' surfaces. The prisms were then split into rough pieces using an EB150X100L breaker (Siebtechnik, Germany) at $50 \mathrm{~Hz}$ and $4 \mathrm{~kW}$. The material was then further pulverized using a vibratory disk mill (Siebtechnik, Germany) for $18 \mathrm{~s}$. A $2-5 \mathrm{~g}$ quantity of powder was put into $32 \mathrm{~mm}$ aluminum cups and pressed in a Fluxana Vaneox PR-40 hydraulic press for $60 \mathrm{~s}$ at $125 \mathrm{~N} / \mathrm{mm}^{2}$. In the case of $\mathrm{pC}$, the material was taken directly from the cement bag, homogenized and pressed in the same way as pHCP. All powders and the pressed pellets were packed airtight and dry and stored over drying agents until the LA-ICP-MS analysis.

\subsection{Material characterization}

Prior to the LA-ICP-MS investigation, the material used in this study was fully characterized according to standard material characteristics:

The mineralogical composition was determined after 56 days by X-ray diffraction with Bruker Advance D8 diffractometer with $\theta-\theta$ configuration and $\mathrm{CuK} \alpha$ irradiation $(\lambda=1.54 \AA$ ), including a $1 \mathrm{~d}$ detector LYNXEYE XE-T. Quantitative phase evaluation was done according to the Rietveld method. The chemical composition was determined with reference to the European standard procedure (DIN EN 196-2) using an ICP-OES Perkin Elmer Avio 500 following digestion in lithium metaborate melt and consecutive dissolution in nitric acid. All results are presented in wt\% for cement (CEM I 42.5 R, Schwenk Cement) and HCP in Table 1. Approximately 30\% unreacted cement phases were found in the HCP.

The porosity and pore size distribution of the HCP were determined by mercury intrusion porosimetry using a Micromeritics AutoPore III device with pressures from 0.004 to $400 \mathrm{MPa}$. This made it possible to measure pore diameters from $1.6 \mathrm{~nm}$ to $0.5 \mathrm{~mm}$. Before the measurement, samples were stored in isopropanol for seven days and dried to constant mass at $40{ }^{\circ} \mathrm{C}$. All values are the mean of two measurements.

The overall porosities and the detailed pore size distributions of HCPs with various $w / c$ ratios are shown in Table 2. Overall porosity and the amount of capillary pores increase as the $w / c$ ratios increase, which is in line with the literature [45]. An overall porosity of approximately $15 \mathrm{vol} \%$ was measured for low $w / c$ ratios. Increasing the amount of water yields an increase in overall porosity up to approximately $25 \mathrm{vol} \%$ for $w / c 0.45$ and 0.50 respectively. $\mathrm{pHCP}$ has lower porosity than $\mathrm{HCP}$, while the ratio of capillary pores increases. In contrast, $\mathrm{pC}$ has a high porosity with mostly capillary pores. If $\mathrm{HCP}$ or $\mathrm{pHCP}$ is heated to $550{ }^{\circ} \mathrm{C}$, the overall porosity nearly doubles, while primarily capillary pores seem to form, as, for instance, portlandite crystals in the $\mu \mathrm{m}$-range disappear and create free space [46]. Delimitations between pore types in concrete are a subject of intense discussion; however, the delimitation according to Setzer was used as a guide here [47].

Prior to the preparation of pressed pellets for $\mathrm{pHCP}$, the size of the powder particles used was determined in the measuring range between $0.02 \mu \mathrm{m}$ and $2 \mathrm{~mm}$ to volumetric d50 $=23 \mu \mathrm{m}$ with a Mastersizer2000 laser granulometer made by Malvern Instruments Ltd.

\subsection{Laser ablation}

Laser Ablation was done with a ns Nd:YAG laser at the quintupled wavelength of $213 \mathrm{~nm}$. Helium was 
Table 1 Mineralogical composition and chemical composition of cement and HCP w/c 0.40

\begin{tabular}{|c|c|c|c|c|c|}
\hline Min. phase & Cement (wt\%) & $\mathrm{HCP} w / c 0.40(\mathrm{wt} \%)$ & Chemical component & Cement (wt\%) & $\mathrm{HCP} w / c 0.40$ (wt $\%)$ \\
\hline $\mathrm{C}_{3} \mathrm{~S}$ & 59 & 11 & Loss of ignition & $1.71^{\mathrm{b}}$ & $18.76^{\mathrm{c}}$ \\
\hline $\mathrm{C}_{2} \mathrm{~S}$ & 13 & 13 & $\mathrm{CaO}$ & 63.14 & 54.95 \\
\hline $\mathrm{C}_{3} \mathrm{~A}$ & 7 & 1 & $\mathrm{SiO}_{2}$ & 20.23 & 17.81 \\
\hline $\mathrm{C}_{4} \mathrm{AF}$ & 9 & 5 & $\mathrm{Al}_{2} \mathrm{O}_{3}$ & 5.00 & 4.56 \\
\hline Periclase & 1 & & $\mathrm{Fe}_{2} \mathrm{O}_{3}$ & 2.76 & 2.43 \\
\hline Calcite & 2 & 1 & $\mathrm{SO}_{3}$ & 3.32 & 3.13 \\
\hline Dolomite & 1 & & $\mathrm{MgO}$ & 1.83 & 1.79 \\
\hline Gypsum & 3 & & $\mathrm{~K}_{2} \mathrm{O}$ & 0.72 & 0.55 \\
\hline Bassanite & 1 & & $\mathrm{P}_{2} \mathrm{O}_{5}$ & 0.37 & 0.32 \\
\hline Anhydrite & 2 & & $\mathrm{TiO}_{2}$ & 0.27 & 0.25 \\
\hline Quartz & 1 & 1 & $\mathrm{Na}_{2} \mathrm{O}$ & 0.11 & 0.09 \\
\hline Amorphous & & $45^{\mathrm{a}}$ & $\mathrm{SrO}$ & 0.09 & 0.08 \\
\hline Portlandite & & 16 & $\mathrm{Cl}$ & 0.07 & 0,05 \\
\hline Ettringite & & 7 & $\mathrm{MnO}_{2}$ & 0.05 & 0.04 \\
\hline
\end{tabular}

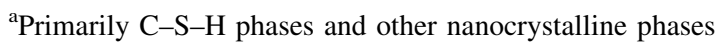

${ }^{\mathrm{b}} \mathrm{Of}$ which $1.53 \%$ is $\mathrm{CO}_{2}$

${ }^{\mathrm{c}}$ Of which $1.40 \%$ is $\mathrm{CO}_{2}$

Table 2 Pore size distributions of HCPs with different $w / c$ ratios

\begin{tabular}{|c|c|c|c|c|c|}
\hline $\begin{array}{l}\text { Sample } \\
\text { type }\end{array}$ & $\begin{array}{l}w / \\
c \text { ratio }\end{array}$ & $\begin{array}{l}\text { Total } \\
\text { porosity }\end{array}$ & $\begin{array}{l}\text { Ratio rough pores }(\%) \\
>75 \mu \mathrm{m}\end{array}$ & $\begin{array}{l}\text { Ratio capillary pores }(\%) \\
75-0.07 \mu \mathrm{m}\end{array}$ & $\begin{array}{l}\text { Ratio gel pores }(\%) \\
<0.07 \mu \mathrm{m}\end{array}$ \\
\hline $\mathrm{HCP}$ & 0.25 & 15.04 & 19.03 & 11.88 & 69.09 \\
\hline $\mathrm{HCP}$ & 0.30 & 14.06 & 14.60 & 7.50 & 77.90 \\
\hline $\mathrm{HCP}$ & 0.35 & 15.93 & 7.11 & 10.88 & 82.01 \\
\hline $\mathrm{HCP}$ & 0.40 & 19.36 & 7.67 & 40.87 & 51.46 \\
\hline $\mathrm{HCP}$ & 0.45 & 25.25 & 7.93 & 40.93 & 51.58 \\
\hline $\mathrm{HCP}$ & 0.50 & 23.70 & 11.31 & 36.07 & 52.62 \\
\hline $\mathrm{HCP}^{550^{\circ} \mathrm{C}}$ & 0.40 & 26.23 & 7.81 & 63.73 & 28.46 \\
\hline $\mathrm{pHCP}$ & 0.40 & 14.68 & 14.59 & 70.55 & 14.86 \\
\hline $\mathrm{pHCP}{ }^{550^{\circ} \mathrm{C}}$ & 0.40 & 28.79 & 5.91 & 70.06 & 24.03 \\
\hline $\mathrm{pC}$ & - & 28.37 & 7.37 & 91.68 & 0.96 \\
\hline
\end{tabular}

used as carrier gas due to its well-known advantages over other transport gases, such as its higher sensitivity for most ICP-MS instruments and smaller particle size distributions [48]. The HCP samples were placed in the sample cell and purged for at least $10 \mathrm{~min}$. All other information is given in Table 3.

The surface of interest was cleaned of sawing and drying residues by pre-ablation, applying a line scan with a maximum spot size of $110 \mu \mathrm{m}$, a scan speed of $70 \mu \mathrm{m} / \mathrm{s}$, and a laser fluence of $2.0 \mathrm{~J} / \mathrm{cm}^{2}$.

To investigate the melting processes on the sample surface, single spot ablation was applied with 200 laser shots at the same position at a frequency of $20 \mathrm{~Hz}$. All other conditions were the same as for line ablation. To visualize the crater bottom during SEM analysis at high fluences $\left(8.3\right.$ and $22 \mathrm{~J} / \mathrm{cm}^{2}$ ), the number of shots was reduced to 50 and 20 , respectively. 
Table 3 Information and measurement conditions relating to laser (left) and ICP-MS (right)

\begin{tabular}{llll}
\hline Laser conditions & & ICP-MS conditions & \\
\hline Laser & ESI NWR 213 Nd:YAG & ICP-MS & NexION 300D Perkin Elmer, USA \\
Cell & 2 Volume cell system & Data aquisition software & NexION ICP MS software \\
Wavelength & $213 \mathrm{~nm}$ & Data aquisition mode & Peak hopping \\
Mode & Fully Q-switched & Detector & Dual (pulse and analog counting) \\
Pulse length & $4-6 \mathrm{~ns}$ & Lens settings & Auto lens on \\
Shot frequency & $20 \mathrm{~Hz}$ & Dwell time & $5 \mathrm{~ms}$ \\
Laser fluence & $1.7-2.0 \mathrm{~J} / \mathrm{cm}^{2}$ & Spectrometer settling time & $0.2 \mathrm{~ms}$ \\
Diameter & $100 \mu \mathrm{m}$ & Carrier gas $(1 / \mathrm{min})$ & $0.7 \mathrm{~L} / \mathrm{min} \mathrm{He}+0.92 \mathrm{~L} / \mathrm{min} \mathrm{Ar}$ \\
Sampling mode & Line & Gas through torch & $10 \mathrm{~L} / \mathrm{min} \mathrm{Ar}$ \\
Scan speed & $30 \mu \mathrm{m} / \mathrm{s}$ & Torch RF power & $1200 \mathrm{~W}$ \\
Line length & $1000 \mu \mathrm{m}$ & Measured isotopes & ${ }^{13} \mathrm{C},{ }^{23} \mathrm{Na},{ }^{25} \mathrm{Mg},{ }^{27} \mathrm{Al},{ }^{29} \mathrm{Si},{ }^{32} \mathrm{~S}$, \\
& & & ${ }^{35} \mathrm{Cl},{ }^{39} \mathrm{~K},{ }^{43} \mathrm{Ca},{ }^{54} \mathrm{Fe},{ }^{88} \mathrm{Sr}$ \\
\end{tabular}

LA-ICP-MS data were baseline- and spike-corrected by in-house software based on Microsoft Excel. The ablated volume was determined with a Keyence VK-X 100 Laser Scanning Microscope. A 3D image of the ablated lines was taken at $10 \times$ magnification and a $\mathrm{z}$-axis resolution of $3 \mu \mathrm{m}$. The volume was determined with the packaged software after equalization and baseline correction. The method was used previously to image line scans by Diwakar [49].

\subsection{Aerosol collection}

Two methods were used to yield particles for subsequent analysis in the SEM:

Method 1: A $0.22 \mu \mathrm{m}$ PTFE or PES filter (only in the case of $\mathrm{pHCP} 22.5 \mathrm{~J} / \mathrm{cm}^{2}$ ) was placed $0.6 \mathrm{~m}$ downstream in the PVC connective tubing, in front of the Y-piece combining the helium laser aerosol and ICP-MS auxiliary gas. After 200 laser shots, the filter was removed and kept in a closed plastic bag until ready for analysis in the SEM.

Method 2: Instead of catching the aerosol directly on the filter, a 300 mesh copper TEM grid was placed on the filter surface. Some aerosol particles were fixed to the grid by adhesion. The grids were removed from the filter just prior to the SEM measurement. The conducting copper TEM grid allows high-resolution investigation of these particles with the electron microscope thanks to the surface charging. Thus, conductive sputtering can be avoided.
In both experimental methods, no significant ICPMS signals from sample elements were recorded during LA-ICP-MS experiments confirming nearcomplete deposition of the aerosol on the filter material. Especially in the second method, no representative aerosol composition was expected on the grid due to large cavities in the grid that enabled most particles to be located on the filter.

\subsection{SEM/EDS}

HCPs were examined in a Jeol JSM-7500F SEM device equipped with an EDS analysis unit operating at high vacuum mode at an accelerating voltage of $0.8 \mathrm{keV}$. The samples were uncoated. The EDS analysis was set up to analyze the following elements: $\mathrm{Na}, \mathrm{Mg}, \mathrm{Al}, \mathrm{Si}, \mathrm{S}, \mathrm{P}, \mathrm{Cl}, \mathrm{K}, \mathrm{Ca}, \mathrm{Mn}, \mathrm{Ti}$ and Fe. Noise peak was excluded.

Additional evaluation was made on a Hitachi FlexSEM 1000 system using a tungsten hairpin cathode operating at $5 \mathrm{kV}$.

\section{Results and discussion}

\subsection{Crater evaluation after spot ablation}

To evaluate the ablation behavior of HCP at different fluences, the craters of spot ablations were investigated with a SEM. Areas with a high degree of melting tend to display fractionation, as hydrodynamic 
sputtering can occur in thick melting layers, resulting in large spherical particles that cannot be processed completely. To visualize the crater bottom at high fluences $\left(8.3\right.$ and $22 \mathrm{~J} / \mathrm{cm}^{2}$ ), the shot number was reduced from 200 to 50 and 20 , respectively.

Figure 1 shows a crater and, in more detail, a crater edge that have been ablated with a very low fluence of $0.4 \mathrm{~J} / \mathrm{cm}^{2}$. The sawn surface where no ablation occured displays the typical heterogeneous and nanocrystalline structure of HCP. No (original) angular-shaped cement grains are visible. (The cement has angular grains of 3-50 $\mu \mathrm{m}$ in size [50]). In all ablated craters, spherical knobby structures are visible, possibly resulting from a special ablation mechanism of nanocrystalline material or else the presence of watercontaining mineralogical phases. A similar structure was found for a silver target subjected to ablation in water by radiation from a femtosecond laser at a fluence of $4.5 \mathrm{~J} / \mathrm{cm}^{2}$ [51]. The effect of water will be considered in more detail later. The ablation craters of other crystalline materials like natural $\mathrm{CaCO}_{3}$ at $213 \mathrm{~nm}$ are not as defined as in the case of HCP [25]. No ablation of plane and defined pieces are visible for HCP material.

As Fig. 2a,b shows, higher fluences yield deeper craters, again, with spherical particles at the bottom and on the wall. However, on the edge of the crater, no appreciable chimney or other melting residues can be observed. The higher magnification reveals that surfaces near the crater edge are covered by a nanostructured, recondensed, fine material.
Figure 2c, d demonstrates the Gaussian-like beam structure with higher energies in the middle and lower energies at the edges [32]. At a fluence of $8.3 \mathrm{~J} / \mathrm{cm}^{2}$, a small chimney is visible as the ablated material is rapidly cooled down and deposited on the cooler edges of the crater. For both 8.3 and $22.0 \mathrm{~J} / \mathrm{cm}^{2}$ ablation fluences and 50/20 shots, no difference to the ablations with lower fluences could be observed despite a nondefined, scraggly crater edge (Figure A4 in SI).

For $22.0 \mathrm{~J} / \mathrm{cm}^{2}$ and 200 shots, crater edges no longer display the initial $100 \mu \mathrm{m}$ spot shape (Fig. 3a). Material from areas outside the spot ablation was carried along during the ablation process. 200 shots deepen the crater until no bottom is visible. In the area (not visible), where the edge is expected, molten areas are visible (Fig. 3a-d). An observable melting process therefore starts at high fluences.

Similar craters could be observed for $\mathrm{pHCP}$ by qualitative visual observation. The knobby structure could also be found on crater bottoms. As the ablation mechanism does not seem to change, the images are not discussed in detail here, but additional details can be found in ESI. To compare the observed behavior to a material with a similar elemental (but not mineralogical) composition, dry cement powder was pressed $(\mathrm{pC})$ and ablated under the same conditions. As mentioned previously, cement is a water-free and high-temperature-sintered material consisting of four definite crystalline phases of calcium silicates and (iron) aluminates milled after cooling to obtain the familiar grey powder.
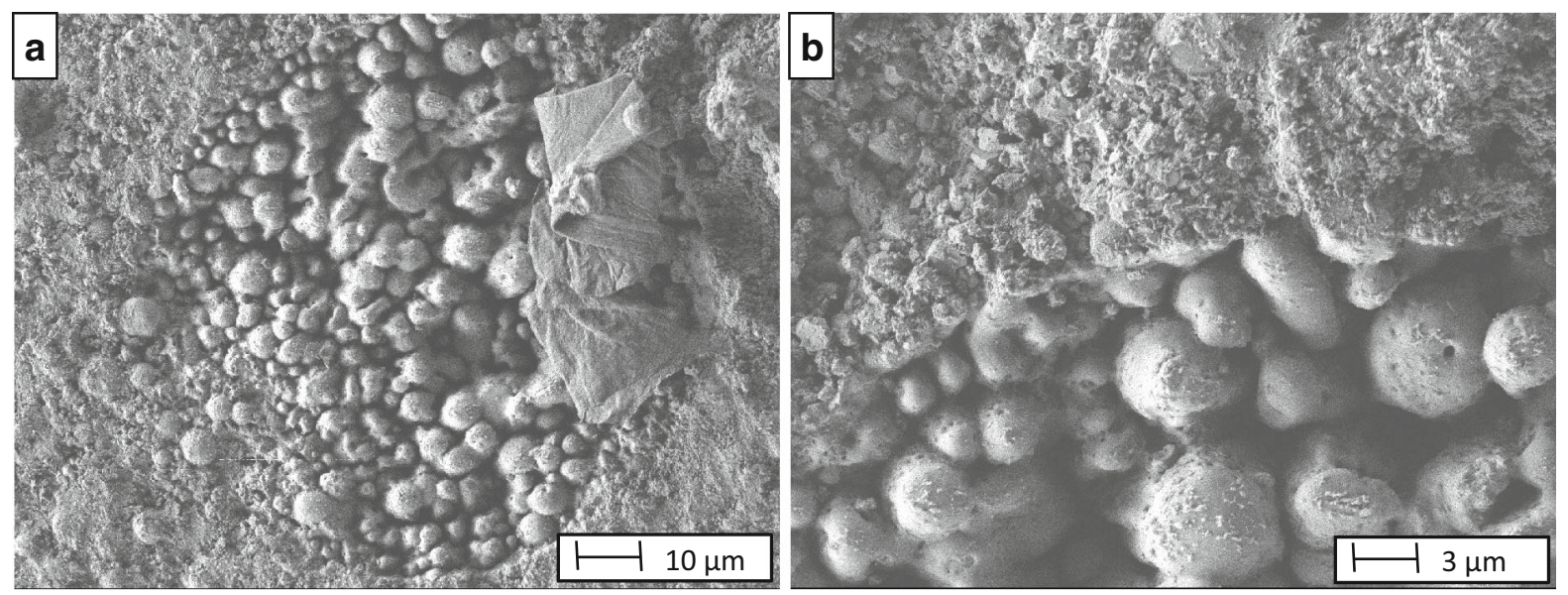

Fig. 1 SEM image of HCP, 200 shots, $0.4 \mathrm{~J} / \mathrm{cm}^{2}$, magnification setting $\times 1000(\mathbf{a}), \times 3000(\mathbf{b})$ 

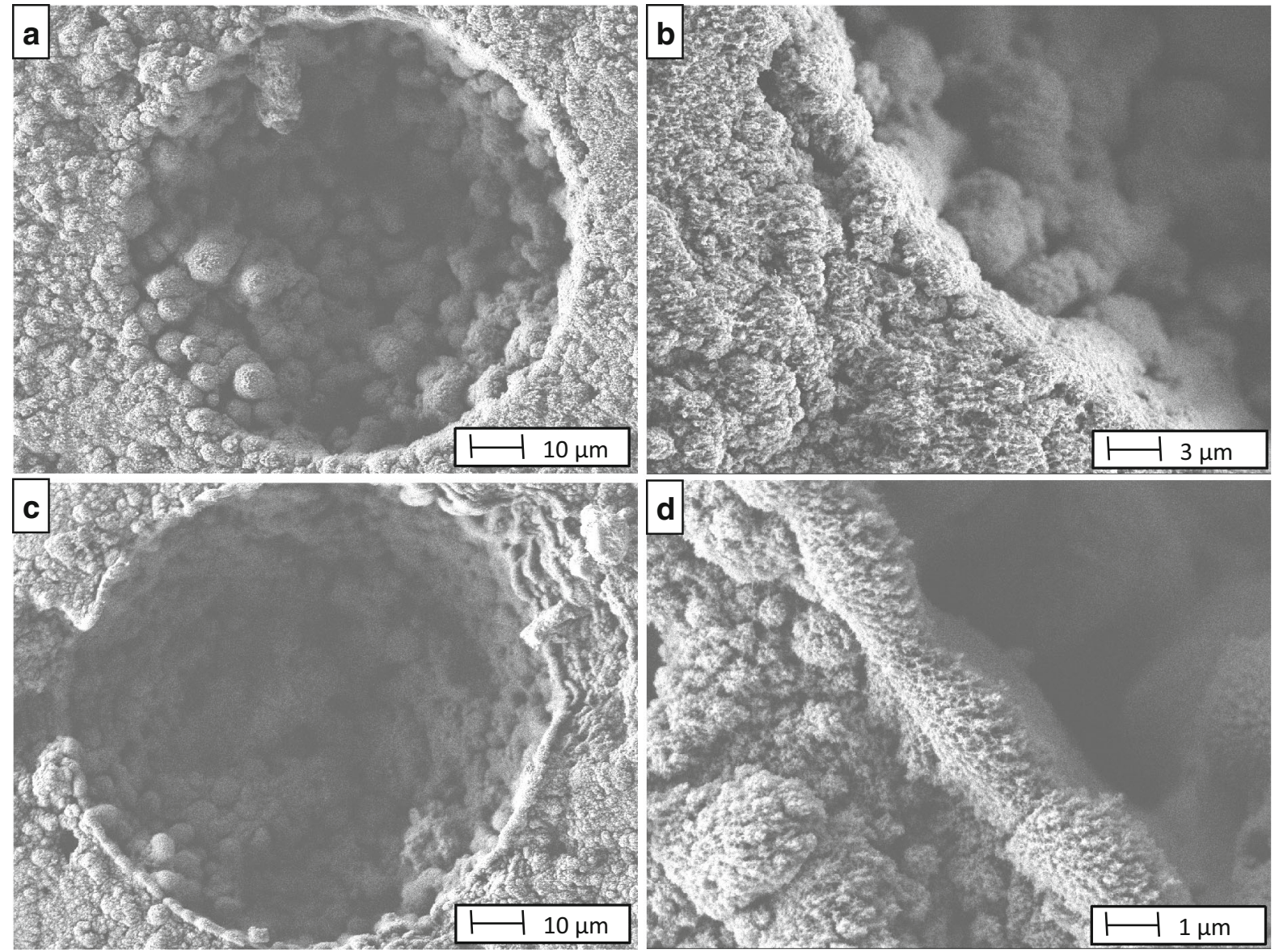

Fig. 2 SEM image of HCP: a, b-200 shots, $2.0 \mathrm{~J} / \mathrm{cm}^{2}$, different magnifications; $\mathbf{c}, \mathbf{d}-50$ shots, $8.3 \mathrm{~J} / \mathrm{cm}^{2}$, different magnifications

The ablation of $\mathrm{pC}$ with low fluences $(0.4$ and $2.0 \mathrm{~J} /$ $\mathrm{cm}^{2}$ ) yields sharp crater edges with no chimneys, while inside the crater, the pressed materials seem to be molten (Fig. 4a, b). Increasing the fluence to 8.3 and later to $22.5 \mathrm{~J} / \mathrm{cm}^{2}$ results in large chimneys and molten material nearly everywhere in the crater and even outside it (Fig. 4c, d). It is possible that small explosions or Kelvin Helmholtz instabilities as discussed in the context of the hydrodynamic sputtering mechanism, may have caused the molten material to move outside of the crater.

The differences between the materials are significant. Pressed cement (pC) displays more melting residues for high fluence ablation and even for low fluence ablation $\left(2.0 \mathrm{~J} / \mathrm{cm}^{2}\right)$, while small melting residues are visible at the edges of the crater. In addition, the knobby structure on the crater bottom is much less pronounced than for HCP. This may be due to the nanostructured composition of HCP containing a lot of water in different states [1]. However, the presence of a large amount of pores (28\%) in $\mathrm{pC}$, primarily in the capillary size range, indicates that pores do not seem to influence the ablation mechanism significantly, as HCP (19\%) and pHCP (15\%) also contain significant, if not so large, amounts of pores as pC.

To investigate the effect of water, $\mathrm{pHCP}$ and $\mathrm{HCP}$ were dried at $550{ }^{\circ} \mathrm{C}$ for $24 \mathrm{~h}$ to remove most of the water from water-containing phases such as portlandite and $\mathrm{C}-\mathrm{S}-\mathrm{H}$ and also to remove pore water [46]. The heating procedure yields a significant change in porosity as seen in Table 2 (pHCP 29\% and HCP 28\%) while nanocrystallinity is still observable in SEM. Thus, the chemical structure has changed while the nanocrystalline structure is still present but with more capillary pores. Craters after ablation with the same settings were again evaluated with an SEM, but no major differences were observed (Fig. 5). Both HCPs 

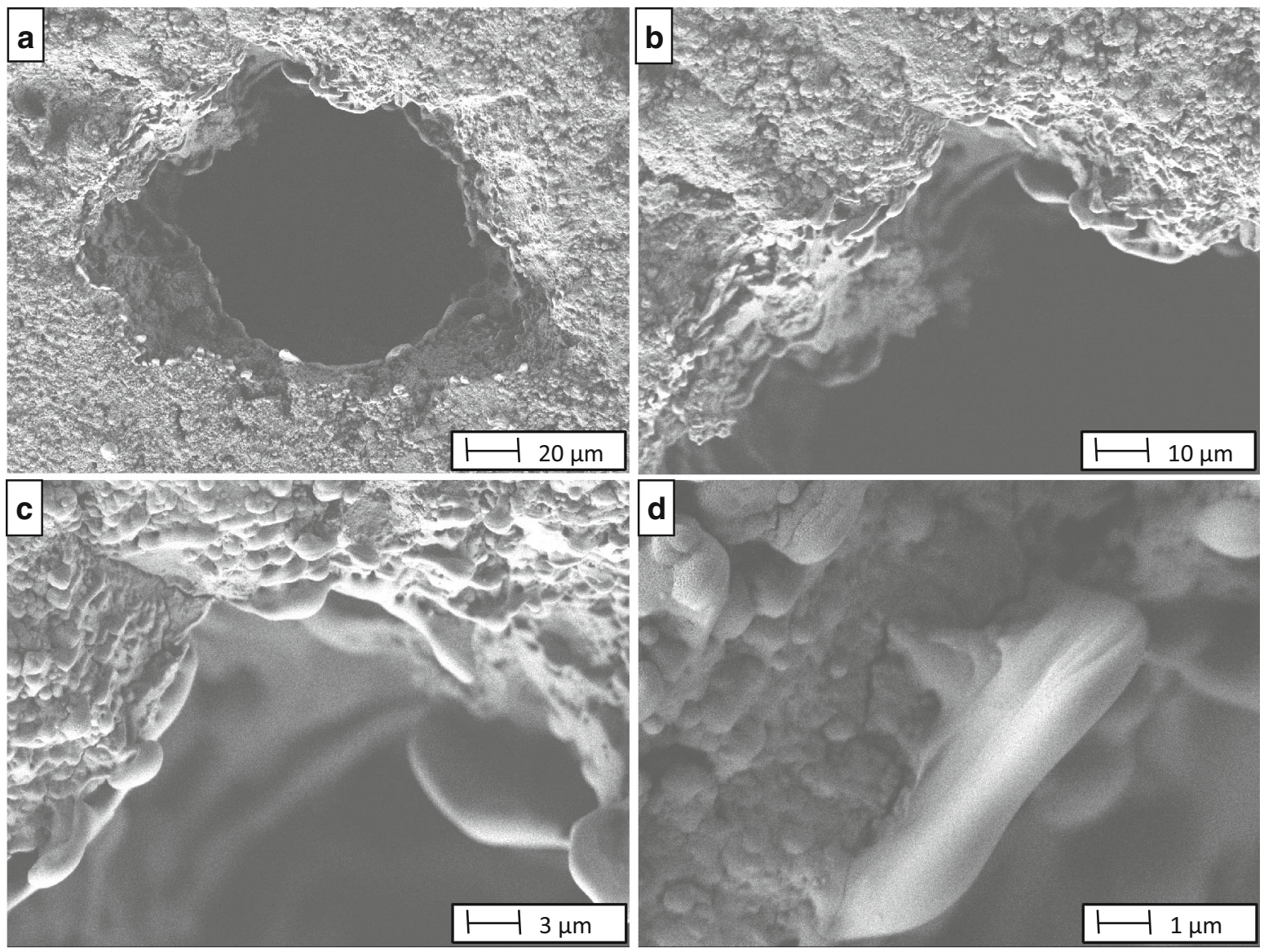

Fig. 3 SEM image of HCP, 200 shots, $22.5 \mathrm{~J} / \mathrm{cm}^{2}$, magnification settings $\times 500(\mathbf{a}), \times 1000(\mathbf{b}), \times 3000(\mathbf{c})$ and $\times 10,000(\mathbf{d})$

display the knobby structure, which is obviously material-specific and most likely attributable to the nanostructured material itself and not the incorporated water.

However, LA-ICP-MS of the nanostructured and porous multiphase material HCP is generally rather special. After crater observation, the aerosol is captured on filters in the gas stream to characterize the particle structure of the ablated material.

\subsection{Aerosol structure of HCP after laser ablation}

Aerosol stream particles from four different HCP ablations with 200 pulses were collected on polymer filters and analyzed by SEM to determine the overall size and shape of the aerosol particles. HCP and pHCP were ablated at 2.0 and $22.5 \mathrm{~J} / \mathrm{cm}^{2}$ respectively. The interpretation of the SEM images is subjective, since the absolute particle numbers or the particle size- related mass could not be determined. In addition, the particles were not distributed fully randomly over the filter surface, possibly because of gas permeability inhomogeneities of the filter surface.

However, all four of the HCP samples investigated yield similar results. Two types of particles can be observed on the filter as evidence of two fundamentally different particle generation mechanisms: separate spherical particles with varying sizes of between 0.1 and $1 \mu \mathrm{m}$, and highly agglomerated/condensed fine structures (Fig. 6). The fine structures resulting from HCP ablation, most probably caused by the mechanism of melting condensation, are slightly different to those fine structures familiar from NIST 610 or the dark basaltic glasses investigated so far [31]. The measurements of the fine structures on copper TEM grids (Fig. 7) permit a rough size estimation of $10-50 \mathrm{~nm}$ compared to less than $10 \mathrm{~nm}$ for the glass matrices [38]. For fine structures, 

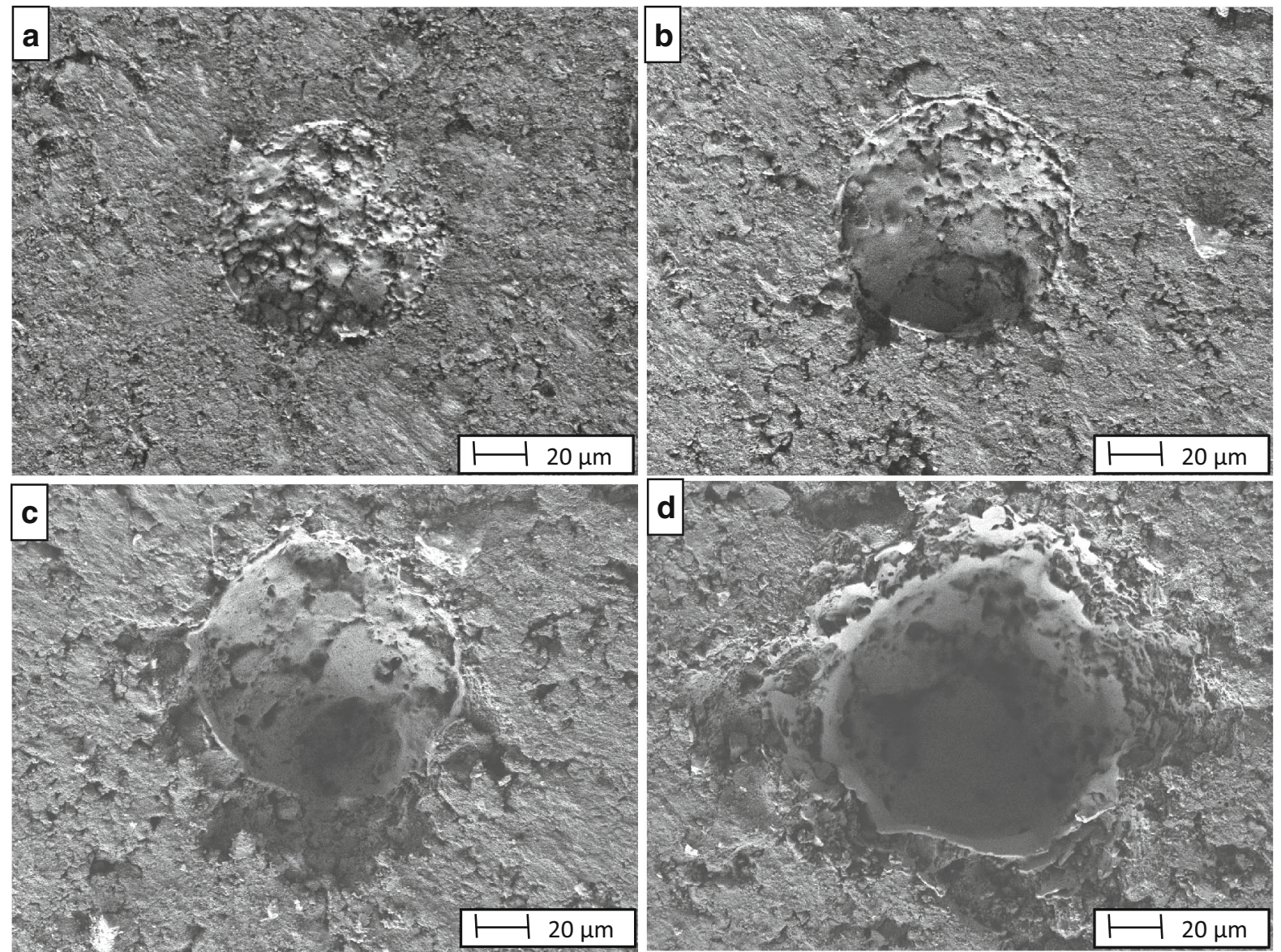

Fig. 4 SEM image of pC, 200 shots, $0.4\left(\right.$ a), $2.0(\mathbf{b}), 8.3(\mathbf{c}), 22.5 \mathrm{~J} / \mathrm{cm}^{2}$ (d), magnification settings $\times 500$
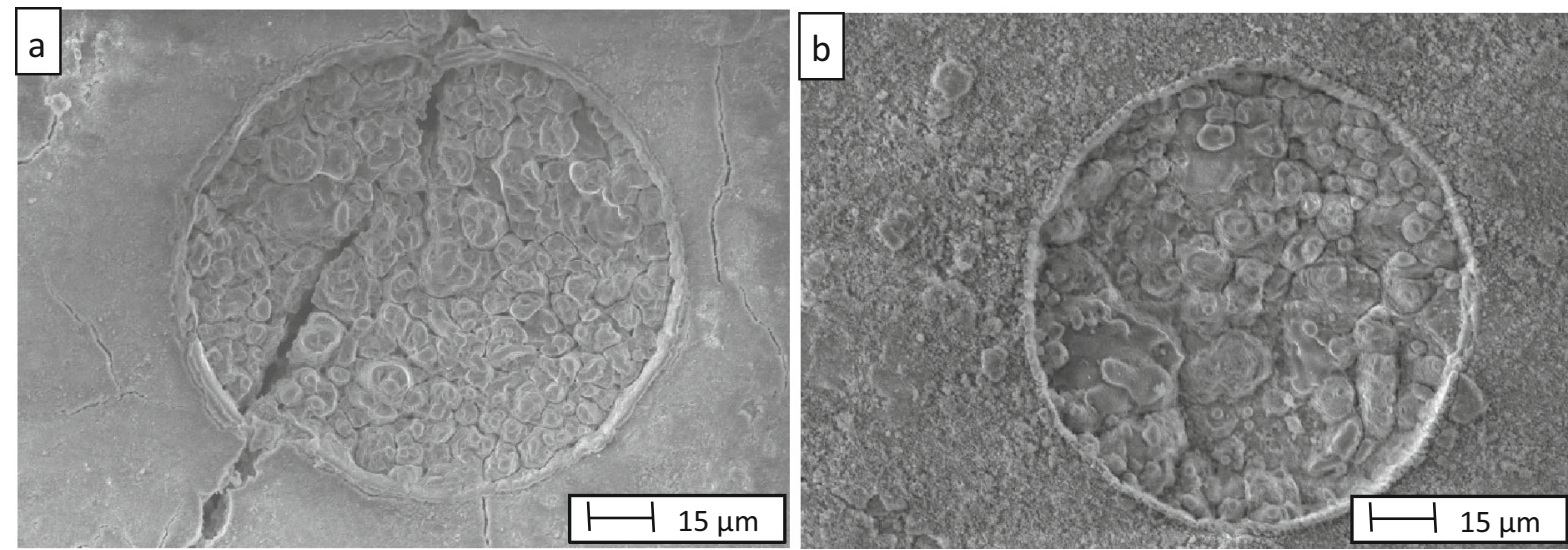

Fig. 5 SEM image of pHCP (a) and HCP (b) 200 shots $2.0 \mathrm{~J} / \mathrm{cm}^{2}$, after drying at $550{ }^{\circ} \mathrm{C}$ for 24 h, magnification settings $\times 800$

no fundamental differences between the four experiments could be observed. Due to their small size, it is expected that they will be fully processed by ICP (completely vaporized, atomized, and transformed into ions), thus, they do not tend towards fractionation in the ICP-MS. 

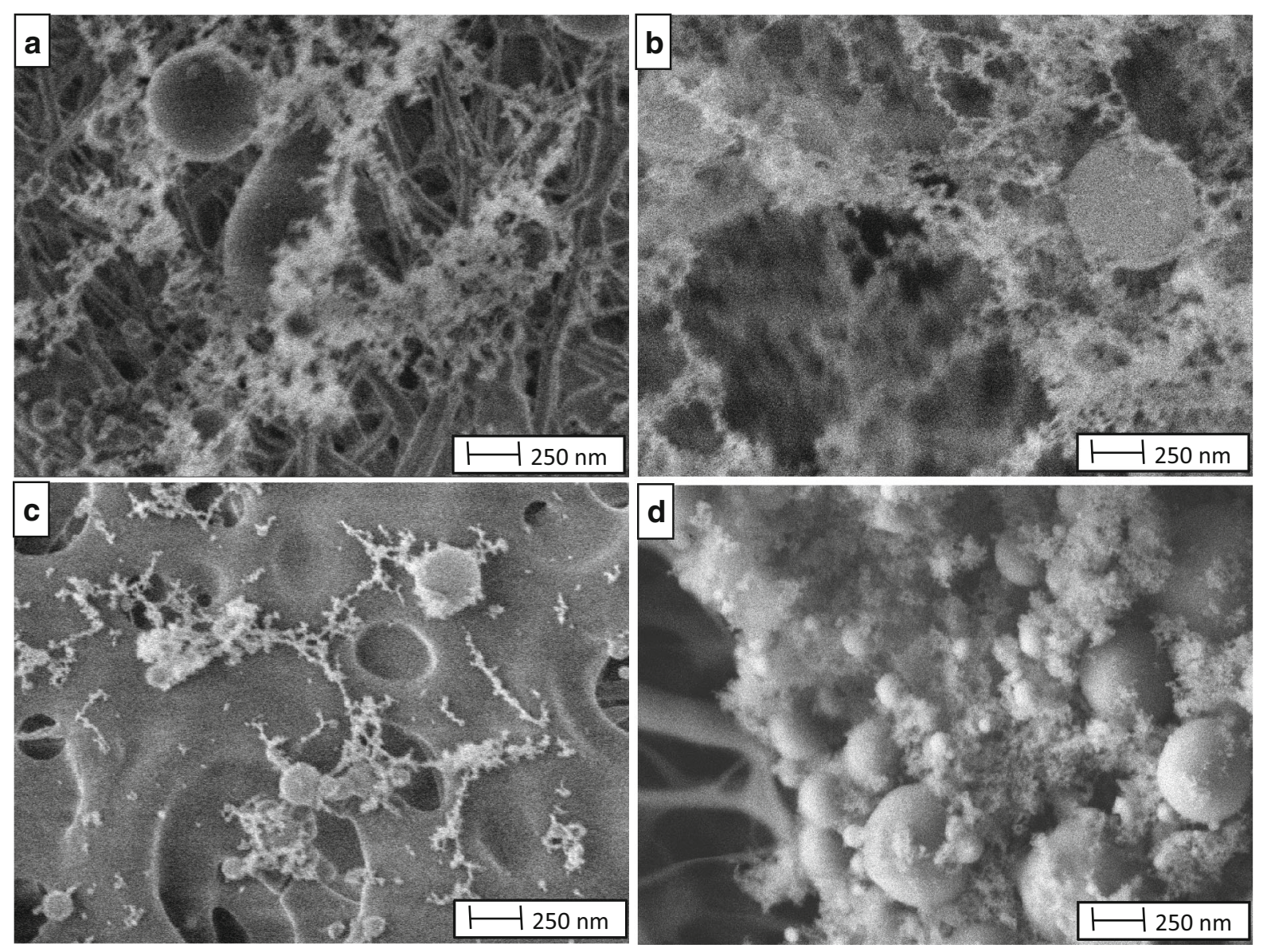

Fig. 6 Aerosol structures after LA on pHCP and HCP at magnification setting $\times 40,000: \mathrm{pHCP} 2.0 \mathrm{~J} / \mathrm{cm}^{2}(\mathbf{a}) ; \mathrm{HCP}^{2.0} \mathrm{~J} / \mathrm{cm}^{2}(\mathbf{b})$; $\mathrm{pHCP} 22.5 \mathrm{~J} / \mathrm{cm}^{2}$ (c); HCP $22.5 \mathrm{~J} / \mathrm{cm}^{2}$ (d)

Spherical particles, the result of a hydrodynamic sputtering mechanism, are detected after ablation with high or low fluence and are smaller than those observed for glass at $213 \mathrm{~nm}$ [38]. Nevertheless, there seem to be more particles that are spherical after applying a fluence of $22 \mathrm{~J} / \mathrm{cm}^{2}$ (Fig. 6a-d). This matches the findings in the literature relating to other silicate materials such as glass. It was not possible to conduct EDS analysis to determine the chemical composition of the two particle types or to investigate elemental fractionation due to the overlap of fine structures and spherical particles but ensured the material being the result of HCP ablation (Check ESI). The aerosol particles from $\mathrm{pHCP}$ appear to be equal to those from HCP, so milling and pressing seem to have no influence on the observable aerosol (Fig. 6a-d).

With regard to crater and aerosol characterization, no major differences between the investigated fluences were observed. However, fractionation also takes place in the ICP, influencing the detected signal. The ICP-MS signal at different fluences is therefore now taken into account.

\subsection{Optimum fluence determination for ablation on HCP}

To obtain a basic insight into the laser matter interaction of an unknown material fluence-to-signal ratios were determined to find the optimum ablation fluence with low fractionation. Often, an optimum fluence for laser ablation is found between the ablation threshold (if one exits) and the rollover point [52]. Selecting this fluence will lead to high sensitivity with minimal elemental fractionation. Borisov states that a suitable fluence range results in a proportional change of processable particles, and in turn, a linear 

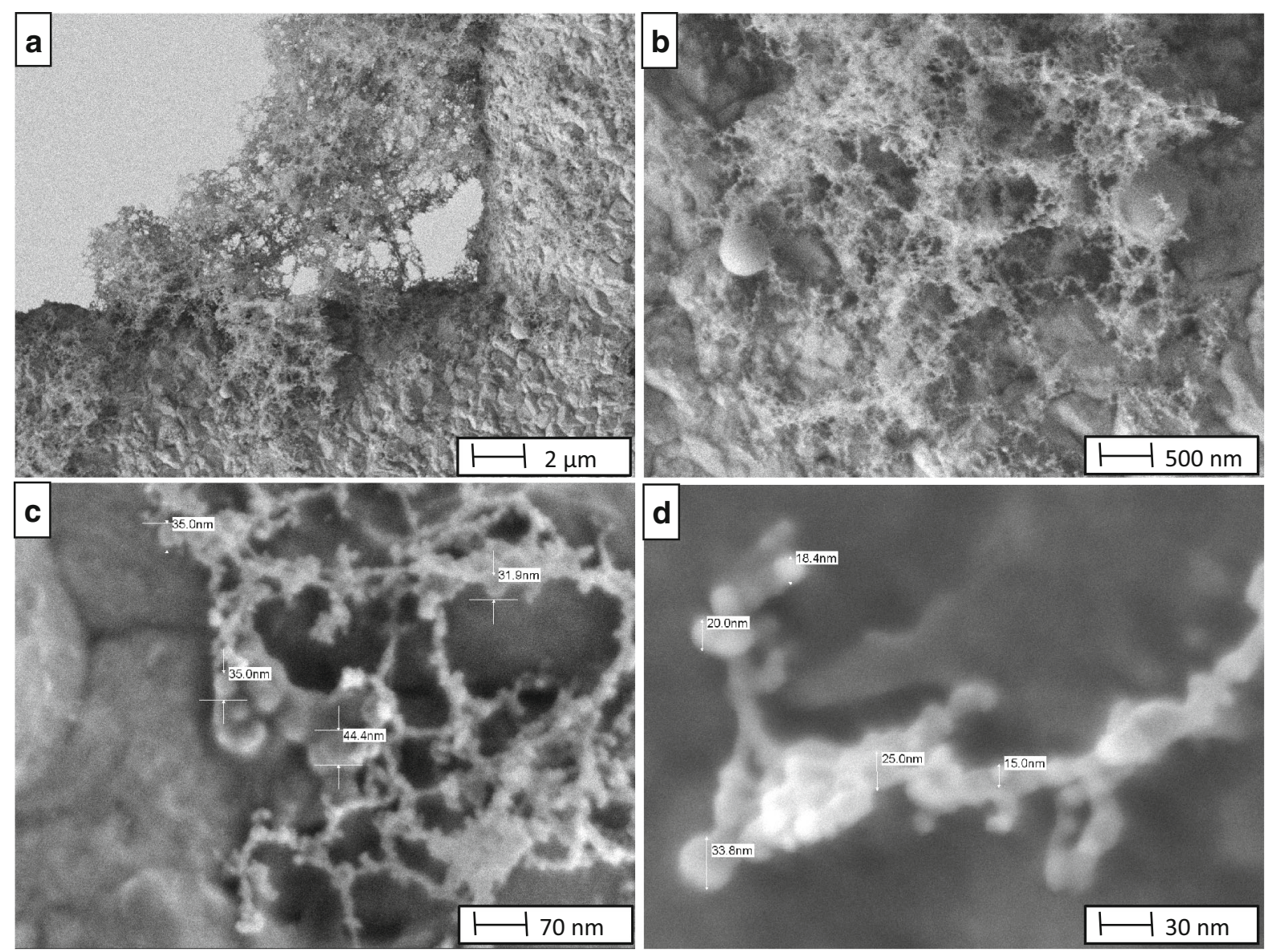

Fig. 7 Aerosol structures captured on copper grids to avoid charge effects at increasing magnification settings: $\times 5000($ a) $\times 20,000$ (b); $150,000(\mathbf{c}) ; \times 300,000(\mathbf{d})$

dependence of the ICP-MS signal [53]. Above an optimum ablation fluence, a roll-over point was found, at which increasing fluence no longer increases the signal proportionally. Often, the source of fractionation remains unknown. A change of ablation mechanism could indicate fractionation during ablation while too large particles or too much material yield fractionation in the plasma [54]. However, fractionation is rather hard to exclude completely with the $213 \mathrm{~nm}$ ns LA system used here [35, 55, 56].

Although ICP-MS instrument parameters, especially plasma power, have a significant effect on fractionation, since it significantly influences atomization and ionization [54]. In our case, plasma power was set empirically to $1200 \mathrm{~W}$ for optimized ionization (low oxide rate). This parameter is not evaluated further so as not to exceed the scope of this work.
Every ablated line (length $1 \mathrm{~mm}$ ) yielded 527 data points for each isotope signal. The lines were subdivided into four sections of equidistant data point numbers, of which the mean was calculated for each section. Data points/lines and standard deviations as displayed in Fig. 10 were calculated from these four mean values, respectively.

Figure 10 shows a comparison between the ${ }^{43} \mathrm{Ca}$ ICP-MS signal intensities of NIST 612 glass, HCP $w /$ $c 0.40, \mathrm{pHCP} w / c 0.40$ and $\mathrm{pC}$ with increasing fluence from $<0.2 \mathrm{~J} / \mathrm{cm}^{2}$ to approximately $19 \mathrm{~J} / \mathrm{cm}^{2}$. Regarding the differences in $\mathrm{Ca}$ content in the materials investigated and in the NIST 612 glass $(\mathrm{CaO}$ content $12.00 \mathrm{wt} \%$ for NIST $612, \sim 65 \mathrm{wt} \%$ for HCP materials), the $\mathrm{Ca}$ signal value of NIST 612 glass was quintupled to obtain a comparable scale in the graph. A commonly occurring fluence range for LA-ICP-MS applications on glass (especially NIST glass) is 
between 5 and $10 \mathrm{~J} / \mathrm{cm}^{2}$, while it is not yet defined for HCP materials. Considerable fluctuations for cementitious materials are due to heterogeneity of the sample matrix at operating spot sizes of $100 \mu \mathrm{m}$. An ablation threshold could not be detected for any material except the NIST glass, as previously reported for glass in the literature [57]. All other materials also yield a detectable signal at very low fluences. Significant craters at the fluence of $0.40 \mathrm{~J} / \mathrm{cm}^{2}$ underline this observation. Thus, the ablation at low fluences of cement materials (refers to HCPs and pC) seem to differ significantly compared to NIST 612 glass. This is attributed to other light absorption properties as well as to the nanostructured sample composition, where the incoming laser energy is transformed to heat in a very small and limited volume in the fine crystalline needles, enabling ablation to commence independently of the energy quantity.

In the signal intensity to fluence diagram (Fig. 8) $\mathrm{HCP}$ and pHCP (different pore structures, same nanostructure, same $w / c$ ratio) show similar signal responses with increasing fluence. Both graphs can be divided into three fluence sectors:

For low fluences of $<1 \mathrm{~J} / \mathrm{cm}^{2}$, the signal is low and non-linear. This sector seems to be dominated by inconstant ablation. However, no ablation threshold is detectable.

For medium fluences of $1-6 \mathrm{~J} / \mathrm{cm}^{2}$, ICP-MS signals increase proportionally with increasing fluences. More material is ablated due to the higher energies yielding higher ICP-MS signals. This proportional behavior is an indication of constant ablation mechanisms and continuous processes in the plasma in this fluence sector.

For fluences higher than $\sim 6 \mathrm{~J} / \mathrm{cm}^{2}$, signals are still increasing with higher fluences but not as much as in sector 2. Possible reasons are less effective mass removal and transport, different particle formation mechanisms, fractionation in the plasma, or a combination of these. A detailed investigation of these effects is beyond the scope of this paper.

Compared to the nanostructured HCP (both for $\mathrm{HCP}$ and $\mathrm{pHCP}$ ), $\mathrm{pC}$ has no significant nanostructure and it has a higher calcium content, as the material is not mixed with water. However, the ICP-MS signals corresponding to $\mathrm{pC}$ are lower and their behavior is different to that of HCP signals: the $\mathrm{Ca}$ signal increases constantly and proportionally (but not as steeply as HCP in sector 2) throughout the entire applied fluence range up to $19 \mathrm{~J} / \mathrm{cm}^{2}$, at which point the ICP-MS signal is as high as for the HCP materials. The differing signal behavior is probably due to the different ablation mechanism observed on the ablation craters. However, for porous materials, Hilbig et al. [58] suggested that the material loss may be due to the deposition of ablated aerosol in the porous network of their investigated filter material. In the case of HCP and pHCP, this is likely to happen, as the craters show no melting residues, especially for low fluences. For higher fluences and for $\mathrm{pC}$ in general, the pores seem to be fused and melted after ablation, so consecutive ablation on a melted spot is more likely to occur in a non-porous material with no aerosol loss. Thus, the signal/energy behavior is likely to differ between the materials investigated.

The signal behavior of NIST 612 glass can also be divided into the same three sectors. However, an ablation threshold can be observed for NIST glass, as the signal starts to increase significantly when applying a laser fluence of more than $1 \mathrm{~J} / \mathrm{cm}^{2}$. The signal is then increases proportionally with increasing fluence up to $\sim 8 \mathrm{~J} / \mathrm{cm}^{2}$. For higher fluences, the ICP-MS signals increase more slowly (and more slowly than for HCP materials), thus, fractionation is highly pronounced [22]. This has previously been reported in the literature and is due to a shift towards an ablation mechanism based more on hydrodynamic sputtering. The different signal to fluence behavior compared to cementitious materials is due to significant differences in the material structure as well as in the physical and chemical composition.

Thus, the proportional range of approx. $2 \mathrm{~J} / \mathrm{cm}^{2}$ was chosen for the working fluence for routine ablation on HCP materials. However, for the main chemical constituents, elemental fractionation should be investigated to ensure that a universal setup can be drawn for other major elements.

\subsection{Elemental fractionation}

To investigate fractionation, element signal ratios can be compared to each other at different fluences. Fractionation indices (FIs) are commonly calculated according to Fryer for homogeneous materials to evaluate fractionation over time [59]. However, due to the inhomogeneity of $\mathrm{HCP}$, the measurement of classic FIs is not valid. Fractionation was also examined with elemental ratios at different fluences 


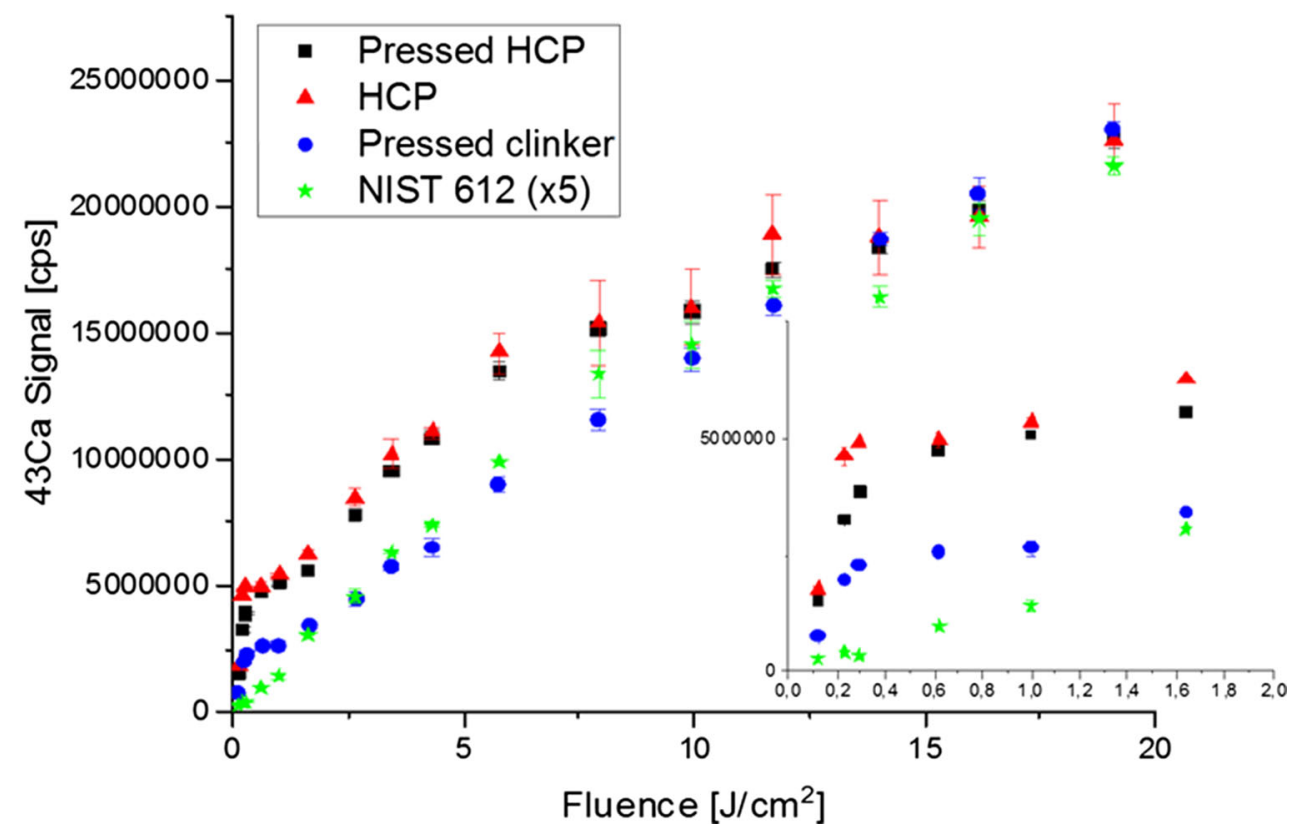

Fig. 8 Relationship between laser fluence and detected calcium ICP-MS signal intensity for a spot size of $100 \mu \mathrm{m}$ on NIST 612 glass, $\mathrm{HCP} w / c 0.40$, pHCP $w / c 0.40$ and $\mathrm{pC}$

as Borisov et al. did for pressed pellet surrogates [53] or Kühn for brass [22]. Borisov et al. analyzed pressed mixtures of homogeneously distributed $\mathrm{PbO}$ and $\mathrm{CeO}_{2}$ in a $\mathrm{PE}$ binder. Due to the different boiling points of the two materials $\left(\mathrm{PbO} 886{ }^{\circ} \mathrm{C} ; \mathrm{CeO}_{2} 2600{ }^{\circ} \mathrm{C}\right.$ ), the $\mathrm{Pb} / \mathrm{Ce}$ ratio was investigated with different fluences. Herein, the present form of the elements (solid, as metal or oxide etc.) is essential for this consideration when focusing on the boiling point. The authors describe a fluence range in which fractionation is minimized and recommend a fluence in this range for LA-ICP-MS analysis. Outside this range, the elemental ratio is not constant. Elements used for this evaluation need to be present in a detectable amount with low background (interferences) and in a homogeneous distribution, which is only the case for the major constituents of $\mathrm{HCP}$ and $\mathrm{pC}$.

In Fig. 9, element signals of both major constituents of HCP (calcium and silicon, see Table 4) whose oxides $\left(\mathrm{CaO}\right.$ and $\left.\mathrm{SiO}_{2}\right)$ have a boiling point difference of more than $1100 \mathrm{~K}$, are compared at different fluences. However, in the case of HCP, the presence of the elements as separate pure oxides is actually not correct, since, for example, in a $\mathrm{C}-\mathrm{S}-\mathrm{H}$ phase, the silicon is not present as $\mathrm{SiO}_{2}$, but as a condensed chain with bound water and $\mathrm{Ca}$ as the counter ion [3]. However, when heated strongly (in the case of LA), it can be assumed that before entering the vapor phase and after the chain structure has been destroyed, the elements are present in a melted layer, which consists of a mixture of all elemental oxides. Therefore, the boiling temperatures of the oxides are looked at here. For other ratios of major HCP constituents, their oxides have no significant boiling point differences (e.g. Ca vs. $\mathrm{Al}$ only $130{ }^{\circ} \mathrm{C}$ ) while a comparison with minor and trace elements is inappropriate due to the local variations in their concentration in the heterogeneous material. Errors are calculated equally, as in Fig. 8. The signal ratio to fluence diagram shows no varying elemental composition for either HCP and pHCP or for pC. However, for NIST 612 , an elemental fractionation is detected for low fluences. This indicates that the cement materials investigated here display no elemental fractionation for the major constituents, irrespective of the fluence. In this conclusion is supported by similar results for the $\mathrm{Al} / \mathrm{Si}$ ratio (Figure $\mathrm{A} 6$ in $\mathrm{SI}$ ). 


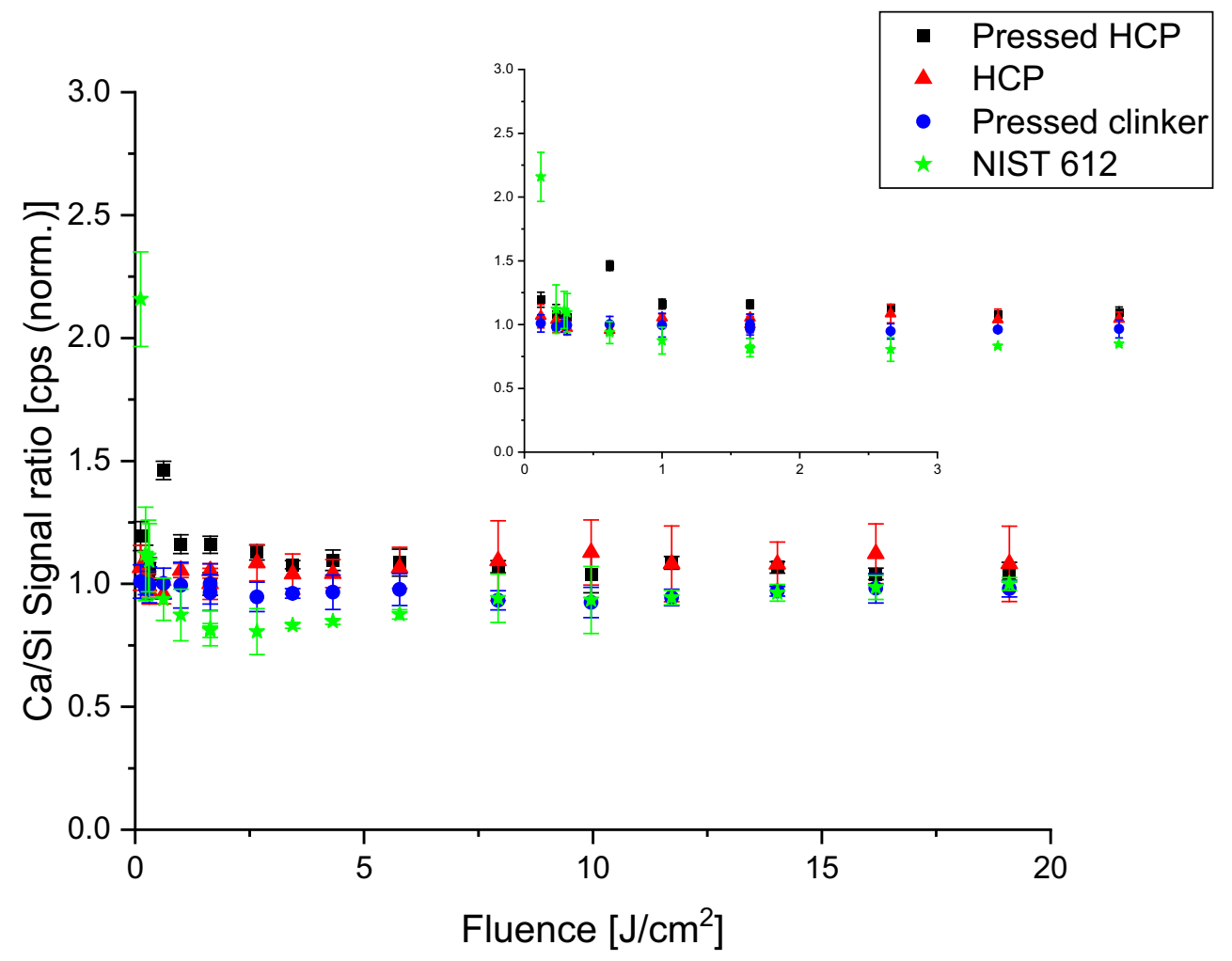

Fig. 9 Calcium to silicon signal ratio at various fluences for $\mathrm{HCP} w / c 0.40, \mathrm{pHCP} w / c 0.40$, pC and NIST 612 glass. For normalization $\mathrm{Ca}$ and $\mathrm{Si}$ was measured twice at $1.64 \mathrm{~J} / \mathrm{cm}^{2}$, whereas the determined $\mathrm{Ca} / \mathrm{Si}$ ratio of the second measurement was set to 1

Table 4 Content of certain elemental oxides in HCP and NIST 612 with their boiling points

${ }^{\mathrm{a}}$ Decomposition

\begin{tabular}{lcccc}
\hline Element oxide & HCP $(w t \%)$ & Cement $(w t \%)$ & NIST 612 (wt $)$ & Boiling point $\left({ }^{\circ} \mathrm{C}\right)$ \\
\hline $\mathrm{CaO}$ & 54.95 & 63.14 & 12.00 & 2850 \\
$\mathrm{SiO}_{2}$ & 17.81 & 20.23 & 72.00 & 1713 \\
$\mathrm{Al}_{2} \mathrm{O}_{3}$ & 4.56 & 5.00 & 2.00 & 2980 \\
$\mathrm{~K}_{2} \mathrm{O}$ & 0.55 & 0.72 & $\sim 0.02$ & $350^{\mathrm{a}}$ \\
$\mathrm{PbO}_{2}$ & $\sim 0.01$ & $\sim 0.01$ & $\sim 0.01$ & 886 \\
\hline
\end{tabular}

\subsection{Influence of pore volume and $w / c$ ratio} on HCP ablation

In $\mathrm{HCP}$, the applied $w / c$ ratio yield a certain pore structure with increasing volume ratio and size of pores when the water content in the mixture is increased (see Table 2). Thus, material-specific parameters such as density, water content and phase composition differ. For a $w / c$ ratio of 0.25 , an overall porosity of approximately $15 \mathrm{vol} \%$ was determined, increasing to approx. $25 \mathrm{vol} \%$ for $w / c 0.45$ and 0.50 respectively. Thus, the density decreases for higher $w /$ $c$ ratios as the amount of water per volume unit increases (see Fig. 10a).

Ablation of three parallel $4 \mathrm{~mm}$ lines on the HCP surfaces yields fluctuating ablated volumes with a tendency towards higher ablated volumes with a higher $w / c$ ratio (see Fig. 10a). The considerable error bar is calculated from the three determined volumes and results from surface and crater roughness and instrumentation limits, already noticeable in other investigations, e.g. [35]. However, the increased ablated volume seems to compensate for the lower density of HCPs with a higher $w / c$ ratio. Thus, the total 
ablated mass is not affected as much as the ablated volume (see Fig. 10b).

Figure $10 \mathrm{~b}$ additionally displays the $\mathrm{raw}{ }^{43} \mathrm{Ca}$ ICPMS signal after drift correction by frequent measurements of NIST glass 612 (other isotope signals see SI, Table A2). Error bars were calculated from the mean Ca signals of the three parallel lines The signal varies from $\sim 90,000 \mathrm{cps}$ at $w / c 0.40$ to $\sim 130,000$ at $w /$ c 0.50 . No influence of the $w / c$ ratio is observable, while low errors indicate a high precision. However, a slight correlation to the ablated mass might be interpreted. The $\mathrm{Ca}$ signal per $\mu \mathrm{g}$ of ablated mass was calculated by dividing both parameters.

The variation of the $w / c$ ratio of $\mathrm{HCP}$ also has no noticeable influence on the $\mathrm{Ca}$ signal per $\mu \mathrm{g}$ of material, which is displayed in Fig. 11. However, the calcium content for the six $w / c$ ratios differs because the varying dilutions have to be taken into account to enable comparability. It can be concluded that matrixmatched calibration might be possible with reference HCPs without considering the $w / c$ ratio. An internal standard is recommended, as the signal $/ \mu \mathrm{g}$ ratio is different for the six HCP samples. However, it is necessary to pay careful attention as supplementary cementitious materials (SCMs) like limestone or clays are frequently used nowadays in HCP mixtures, which change the material properties and ablation characteristics significantly [60].

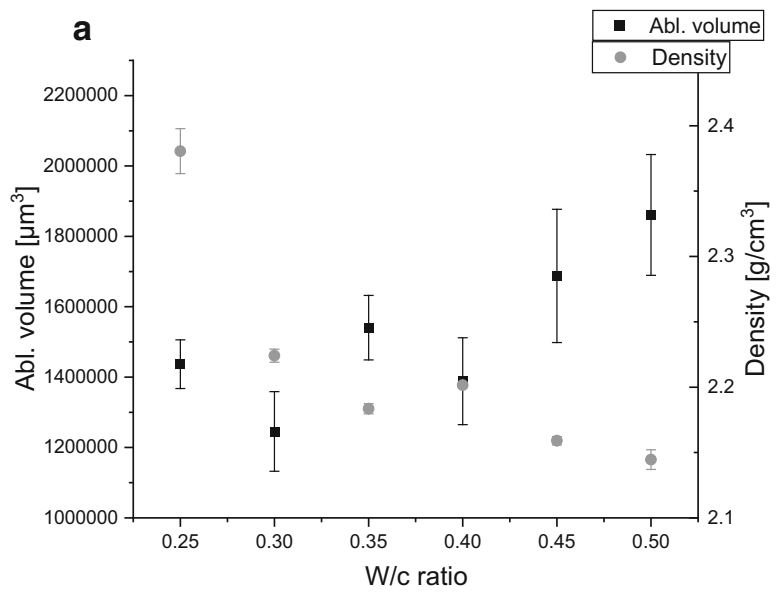

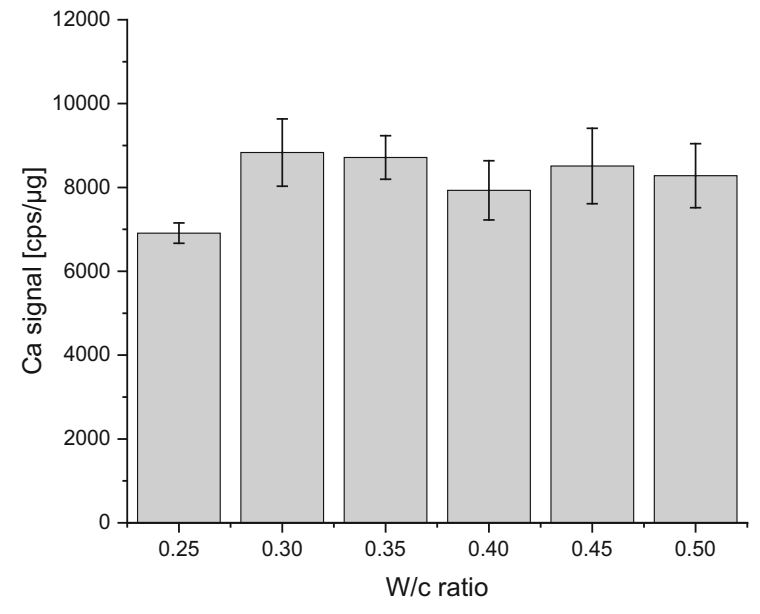

Fig. $11{ }^{43} \mathrm{Ca}$ ICP-MS signal in cps per $\mu \mathrm{g}$ of ablated material as a function of $w / c$ ratio (the variations in calcium content of the samples due to varying dilutions with water were taken into account in the calculation)

\section{Conclusions}

This paper presents fundamental investigations of LAICP-MS on hardened cement paste, a nanostructured, porous and multiphase material. The bottom of ablation craters on HCP material show a characteristic knobby structure. The influence of water on the ablation of HCP and pHCP could be excluded as water-free $\mathrm{HCP}$ treated at $550{ }^{\circ} \mathrm{C}$ shows similar ablation craters. Great differences were observed between the craters of HCP and original cement (pressed to pellets). More ejected material with no nanostructure is visible in and around the craters of the

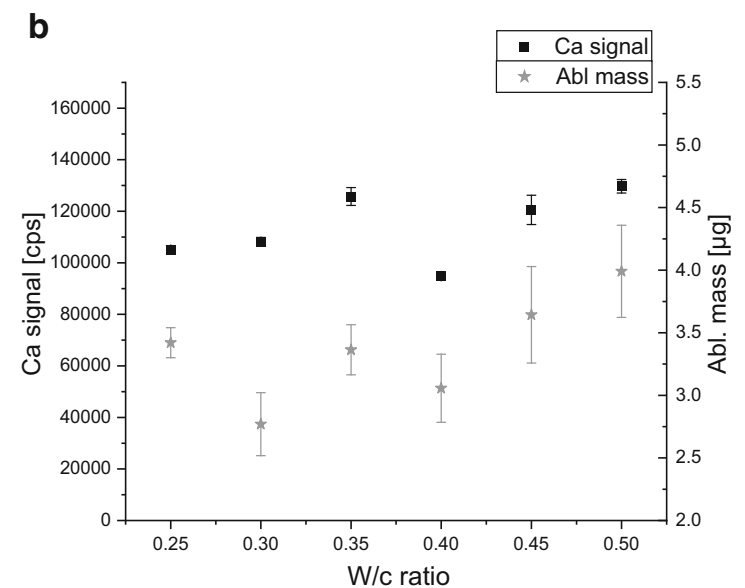

Fig. 10 Ablated volumes and densities (a) and ${ }^{43}$ Ca signal and ablated mass (b) for HCPs with w/c ratios from 0.25 to 0.50

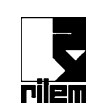


original cement, indicating different ablation characteristics.

Spherical particles with sizes of between 0.1 and $1 \mu \mathrm{m}$ and fine structures of highly agglomerated/condensed particles measuring 10-50 nm were observed. The particle types, size ranges and formation mechanism are familiar from the literature [31]. The size and shape of the particles are unique to cement materials and not comparable with glass; the spherical particles, in particular, are much smaller than for glass. The aerosol particles of the $\mathrm{pHCP}$ pellets seem to be equal to $\mathrm{HCP}$, while at higher energies, more spherical particles are present in both sample types.

Optimization studies of fluence revealed that the ablation behavior of HCPs is not affected as much by fractionation as NIST 612 glass at fluences of $0.2-19 \mathrm{~J} / \mathrm{cm}^{2}$. Again, no differences were observed between $\mathrm{HCP}$ and $\mathrm{pHCP}$. However, $\mathrm{pC}$ shows a linear behavior over all fluences, thus, it is less affected by fractionation with increasing energy. The difference between $\mathrm{HCP}$ and $\mathrm{pC}$ is due to mechanism of $\mathrm{pC}$ observed during ablation crater investigation, which is based more on melting. Thus, a fluence range of $\sim 2$ to $\sim 6 \mathrm{~J} / \mathrm{cm}^{2}$ is favorable for LA-ICP-MS analysis with minimal fractionation. No elemental fractionation is visible either for cement or for HCP materials when comparing the two major components, calcium oxide and silicon oxide, with a boiling point difference of more than $1100{ }^{\circ} \mathrm{C}$ at the investigated fluences. As craters, aerosols and the fluence signal diagrams are equal for HCP and $\mathrm{pHCP}$, the ablation characteristics do not seem to change when the HCP structure is ground in a mill and pressed to a pellet, which is a common procedure used to yield in-house reference materials.

The effect on the ablation characteristics of the $w /$ $c$ value of $\mathrm{HCP}$, which is a major parameter in concrete technology and has a significant impact on its performance, was also investigated. It was found that increasing the $w / c$ ratio of HCP results in a slightly higher ablated volume. However, since the density is decreasing the ablated mass as well as the signal seems to be unaffected by the $w / c$ ratio. Thus, a matrixmatched external calibration that is independent of the $w / c$ ratio is most probably possible. However, as the ICP-MS signal differs, an internal standard is recommended.

The detailed knowledge gained in this study helps to evaluate different calibration methods used on HCP and subsequently concrete to support specific investigations of distribution and transport of elements in these systems. However, it is only the first step towards opening LA-ICP-MS to such a complex material. Nowadays, a huge variety of so called supplementary cementitious materials (SCMs) are mixed with HCP [61]. However, the addition of SCMs (sometimes with a volume of more than $50 \mathrm{wt} \%$ ) is changing physical, chemical and mineralogical compositions and most probably also ablation behavior, and therefore needs to be evaluated. Further studies will investigate matrix matching, in particular, with regard to the correct determination of element concentrations.

Author's contributions All authors contributed to the study conception and design. Material preparation, data collection and analysis were performed by JS and MD. The first draft of the manuscript was written by MD and all authors commented on previous versions of the manuscript. All authors read and approved the final manuscript.

Funding Open Access funding enabled and organized by Projekt DEAL. The authors would like to thank the German Research Foundation (DFG, Project Number HE 3217-22-1) for financially supporting this research work.

Data availability The data supporting the findings of this study are available from the corresponding author on request.

\section{Declarations}

Conflict of interest The authors declare that they have no conflict of interest.

Open Access This article is licensed under a Creative Commons Attribution 4.0 International License, which permits use, sharing, adaptation, distribution and reproduction in any medium or format, as long as you give appropriate credit to the original author(s) and the source, provide a link to the Creative Commons licence, and indicate if changes were made. The images or other third party material in this article are included in the article's Creative Commons licence, unless indicated otherwise in a credit line to the material. If material is not included in the article's Creative Commons licence and your intended use is not permitted by statutory regulation or exceeds the permitted use, you will need to obtain permission directly from the copyright holder. To view a copy of this licence, visit http://creativecommons.org/licenses/by/4.0/. 


\section{References}

1. Wong H, Buenfeld N (2009) Determining the water-cement ratio, cement content, water content and degree of hydration of hardened cement paste: method development and validation on paste samples. Cem Concr Res 39(10):957-965

2. Cook RA, Hover KC (1999) Mercury porosimetry of hardened cement pastes. Cem Concr Res 29(6):933-943

3. Taylor HF (1997) Cement chemistry, vol 2. Thomas Telford, London

4. Maes M, De Belie N (2014) Resistance of concrete and mortar against combined attack of chloride and sodium sulphate. Cem Concr Compos 53:59-72

5. Rahimi A, Gehlen C, Reschke T, Westendarp A (2014) Approaches for modelling the residual service life of marine concrete structures. Int J Corros 2014:432472. https://doi. org/10.1155/2014/432472

6. Liu Y, Hu Z, Li M, Gao S (2013) Applications of LA-ICPMS in the elemental analyses of geological samples. Chin Sci Bull 58(32):3863-3878

7. Limbeck A, Galler P, Bonta M, Bauer G, Nischkauer W, Vanhaecke F (2015) Recent advances in quantitative LAICP-MS analysis: challenges and solutions in the life sciences and environmental chemistry. Anal Bioanal Chem 407(22):6593-6617

8. Huber B, Hilbig H, Drewes JE, Müller E (2017) Evaluation of concrete corrosion after short-and long-term exposure to chemically and microbially generated sulfuric acid. Cem Concr Res 94:36-48

9. Huber B, Hilbig H, Mago MM, Drewes JE, Müller E (2016) Comparative analysis of biogenic and chemical sulfuric acid attack on hardened cement paste using laser ablation-ICPMS. Cem Concr Res 87:14-21

10. Bonta M, Eitzenberger A, Burtscher S, Limbeck A (2016) Quantification of chloride in concrete samples using LAICP-MS. Cem Concr Res 86:78-84

11. Silva N, Luping T, Rauch S (2013) Application of LA-ICPMS for meso-scale chloride profiling in concrete. Mater Struct 46(8):1369-1381

12. Gastel M, Becker J, Küppers G, Dietze H-J (1997) Determination of long-lived radionuclides in concrete matrix by laser ablation inductively coupled plasma mass spectrometry. Spectrochim Acta Part B 52(14):2051-2059

13. Disch BA (2013) Novel method for the determination of radionuclides and their precursors in concrete using LAICP-MS. Dissertation, Imperial College London

14. Miliszkiewicz N, Walas S, Tobiasz A (2015) Current approaches to calibration of LA-ICP-MS analysis. J Anal At Spectrom 30(2):327-338. https://doi.org/10.1039/ c4ja00325j

15. Lin J, Liu Y, Yang Y, Hu Z (2016) Calibration and correction of LA-ICP-MS and LA-MC-ICP-MS analyses for element contents and isotopic ratios. Solid Earth Sci 1(1):5-27

16. Rodushkin I, Axelsson MD, Malinovsky D, Baxter DC (2002) Analyte-and matrix-dependent elemental response variations in laser ablation inductively coupled plasma mass spectrometry Part 2. Implications for multi-element analyses. J Anal At Spectrom 17(10):1231-1239
17. Simons C (2009) Polymerbasierte Materialien zur matrixangepassten Kalibrierung bei der Massenspektrometrie mit induktiv gekoppeltem Plasma nach Laserablation. Dissertation, Universität Hamburg

18. Van Heuzen A, Morsink J (1991) Analysis of solids by laser ablation-inductively coupled plasma-mass spectrometry (LA-ICP-MS) - II. Matching with a pressed pellet. Spectrochim Acta Part B At Spectrosc 46(14):1819-1828

19. Hewlett P, Liska M (2019) Lea's chemistry of cement and concrete. Butterworth-Heinemann

20. Claverie F, Fernández B, Pécheyran C, Alexis J, Donard OF (2009) Elemental fractionation effects in high repetition rate IR femtosecond laser ablation ICP-MS analysis of glasses. J Anal At Spectrom 24(7):891-902

21. Koch J, Lindner H, Von Bohlen A, Hergenröder R, Niemax $\mathrm{K}$ (2005) Elemental fractionation of dielectric aerosols produced by near-infrared femtosecond laser ablation of silicate glasses. J Anal At Spectrom 20(9):901-906

22. Kuhn H-R, Günther D (2003) Elemental fractionation studies in laser ablation inductively coupled plasma mass spectrometry on laser-induced brass aerosols. Anal Chem 75(4):747-753

23. Hergenröder R (2006) Hydrodynamic sputtering as a possible source for fractionation in LA-ICP-MS. J Anal At Spectrom 21(5):517-524. https://doi.org/10.1039/ b600705h

24. Russo R, Mao X, Borisov O, Liu H (2000) Influence of wavelength on fractionation in laser ablation ICP-MS. J Anal At Spectrom 15(9):1115-1120

25. Hathorne EC, James RH, Savage P, Alard O (2008) Physical and chemical characteristics of particles produced by laser ablation of biogenic calcium carbonate. J Anal At Spectrom 23(2):240-243

26. Saetveit NJ, Bajic SJ, Baldwin DP, Houk R (2008) Influence of particle size on fractionation with nanosecond and femtosecond laser ablation in brass by online differential mobility analysis and inductively coupled plasma mass spectrometry. J Anal At Spectrom 23(1):54-61

27. Glaus R, Kaegi R, Krumeich F, Günther D (2010) Phenomenological studies on structure and elemental composition of nanosecond and femtosecond laser-generated aerosols with implications on laser ablation inductively coupled plasma mass spectrometry. Spectrochim Acta Part B 65(9-10):812-822

28. Liu C, Mao X, Mao S, Zeng X, Greif R, Russo R (2004) Nanosecond and femtosecond laser ablation of brass: particulate and ICPMS measurements. Anal Chem 76(2):379-383

29. d'Abzac FX, Czaja AD, Beard BL, Schauer JJ, Johnson CM (2014) Iron distribution in size-resolved aerosols generated by UV-femtosecond laser ablation: influence of cell geometry and implications for in situ isotopic determination by LA-MC-ICP-MS. Geostand Geoanal Res 38(3):293-309

30. Shaheen ME, Gagnon JE, Fryer BJ (2014) Femtosecond laser ablation behavior of gold, crystalline silicon, and fused silica: a comparative study. Laser Phys 24(10):106102

31. Kuhn H-R, Günther D (2005) The agglomeration state of nanosecond laser-generated aerosol particles entering the ICP. Anal Bioanal Chem 383(3):434-441

32. Horn I, Guillong M, Günther D (2001) Wavelength dependant ablation rates for metals and silicate glasses using 
homogenized laser beam profiles-implications for LAICP-MS. Appl Surf Sci 182(1):91-102

33. Košler J, Wiedenbeck M, Wirth R, Hovorka J, Sylvester P, Míková J (2005) Chemical and phase composition of particles produced by laser ablation of silicate glass and zircon-implications for elemental fractionation during ICPMS analysis. J Anal At Spectrom 20(5):402-409

34. Eggins SM, Kinsley L, Shelley J (1998) Deposition and element fractionation processes during atmospheric pressure laser sampling for analysis by ICP-MS. Appl Surf Sci 127:278-286

35. Gonzalez J, Mao XL, Roy J, Mao SS, Russo RE (2002) Comparison of 193, 213 and $266 \mathrm{~nm}$ laser ablation ICP-MS. J Anal At Spectrom 17(9):1108-1113. https://doi.org/10. 1039/b202122f

36. Luo T, Ni Q, Hu Z, Zhang W, Shi Q, Günther D, Liu Y, Zong K, Hu S (2017) Comparison of signal intensities and elemental fractionation in $257 \mathrm{~nm}$ femtosecond LA-ICPMS using He and Ar as carrier gases. J Anal At Spectrom 32(11):2217-2225

37. Garcia CC, Lindner H, von Bohlen A, Vadla C, Niemax K (2008) Elemental fractionation and stoichiometric sampling in femtosecond laser ablation. $\mathbf{J}$ Anal At Spectrom 23(4):470

38. Kuhn H-R, Guillong M, Günther D (2004) Size-related vaporisation and ionisation of laser-induced glass particles in the inductively coupled plasma. Anal Bioanal Chem 378(4):1069-1074

39. Kuhn H-R (2005) Laser ablation ICP-MS: fundamental investigations on aerosols generated by laser ablation at ambient pressure. Dissertation, ETH Zürich

40. Bogaerts A, Chen Z, Gijbels R, Vertes A (2003) Laser ablation for analytical sampling: what can we learn from modeling? Spectrochim Acta Part B 58(11):1867-1893

41. Geohegan DB, Puretzky AA, Duscher G, Pennycook SJ (1998) Time-resolved imaging of gas phase nanoparticle synthesis by laser ablation. Appl Phys Lett 72(23):2987-2989

42. Holá M, Ondráček J, Nováková H, Vojtíšek-Lom M, Hadravová R, Kanický V (2018) The influence of material properties on highly time resolved particle formation for nanosecond laser ablation. Spectrochim Acta Part B 148:193-204

43. Kuhn H-R, Koch J, Hergenröder R, Niemax K, Kalberer M, Günther D (2005) Evaluation of different techniques for particle size distribution measurements on laser-generated aerosols. J Anal At Spectrom 20(9):894. https://doi.org/10. 1039/b504563k

44. Callies G, Schittenhelm H, Berger P, Hügel H (1998) Modeling of the expansion of laser-evaporated matter in argon, helium and nitrogen and the condensation of clusters. Appl Surf Sci 127:134-141

45. Winslow DN, Cohen MD, Bentz DP, Snyder KA, Garboczi EJ (1994) Percolation and pore structure in mortars and concrete. Cem Concr Res 24(1):25-37

46. Zhang Q, Ye G (2012) Dehydration kinetics of Portland cement paste at high temperature. J Therm Anal Calorim 110(1):153-158

47. Zech B, Setzer MJ (1989) The dynamic modulus of hardened cement paste. Part 2: Ice formation, drying and pore size distribution. Mater Struct 22(2):125-132
48. Günther D, Heinrich CA (1999) Enhanced sensitivity in laser ablation-ICP mass spectrometry using helium-argon mixtures as aerosol carrier. J Anal At Spectrom 14(9):1363-1368

49. Diwakar PK, Gonzalez JJ, Harilal SS, Russo RE, Hassanein A (2014) Ultrafast laser ablation ICP-MS: role of spot size, laser fluence, and repetition rate in signal intensity and elemental fractionation. J Anal At Spectrom 29(2):339-346. https://doi.org/10.1039/c3ja50315a

50. Garboczi EJ, Bullard JW (2004) Shape analysis of a reference cement. Cem Concr Res 34(10):1933-1937

51. Chichkov B (2010) Influence of beam intensity profile on the aerodynamic particle size distributions generated by femtosecond laser ablation. Laser Part Beams 28:45-52

52. O'Connor C (2007) Development of novel calibration strategies for laser ablation inductively coupled plasma mass spectrometry. Dissertation, Loughborough University

53. Borisov OV, Bannochie CJ, Russo RE (2001) Laser ablation inductively coupled plasma mass spectrometry of pressed pellet surrogates for $\mathrm{Pu}$ materials disposition. Appl Spectrosc 55(10): 1304-1311

54. Guillong M, Günther D (2002) Effect of particle size distribution on ICP-induced elemental fractionation in laser ablation-inductively coupled plasma-mass spectrometry. J Anal At Spectrom 17(8):831-837

55. Guillong M, Horn I, Günther D (2003) A comparison of 266 $\mathrm{nm}, 213 \mathrm{~nm}$ and $193 \mathrm{~nm}$ produced from a single solid state $\mathrm{Nd}$ :YAG laser for laser ablation ICP-MS. J Anal At Spectrom 18(10):1224-1230. https://doi.org/10.1039/b305434a

56. Jeffries TE, Fernandez-Suarez J, Corfu F, Gutierrez Alonso $\mathrm{G}$ (2003) Advances in U-Pb geochronology using a frequency quintupled $\mathrm{Nd}$ :YAG based laser ablation system ( $\lambda$ $=213 \mathrm{~nm}$ ) and quadrupole based ICP-MS. J Anal At Spectrom 18(8):847

57. Rudolph P, Bonse J, Krüger J, Kautek W (1999) Femtosecond-and nanosecond-pulse laser ablation of bariumalumoborosilicate glass. Appl Phys A 69(1):S763-S766

58. Hilbig H, Huber M, Gmell A, Heinz D (2017) Determination of heavy metals in a highly porous sorptive filter material of road runoff treatment systems with LA-ICP-MS. Water Air Soil Pollut 228(9):331

59. Fryer BJ, Jackson SE, Longerich HP (1995) The design, operation and role of the laser-ablation microprobe coupled with an inductively coupled plasma; mass spectrometer (LAM-ICP-MS) in the earth sciences. Can Mineral 33(2):303-312

60. Millar S, Kruschwitz S, Wilsch G (2019) Determination of total chloride content in cement pastes with laser-induced breakdown spectroscopy (LIBS). Cem Concr Res 117:16-22

61. Juenger MC, Siddique R (2015) Recent advances in understanding the role of supplementary cementitious materials in concrete. Cem Concr Res 78:71-80

Publisher's Note Springer Nature remains neutral with regard to jurisdictional claims in published maps and institutional affiliations. 